\title{
O dever dos moços
}

E' Thucydides criticado por Spengler em razão de ter affirmado que, até o anno 400 antes de Christo, nada de importante fez a humanidade, sinão a guerra do Peloponeso. Para o historiador grego, dormiram os nossos avós durante todos os seculos que precederam ao dessa guerra. Não incorro na censura de Spengler a Thucydides. Acredito que só pelo pouco conhecimento das luctas de nossos antepassados, temos a impressão de estarmos, pela primeira vez, a enfrentar problemas sociaes nunca dantes estudados e resolvidos pelos que hoje dormem na paz dos mortos. Os nossos abolicionistas tiveram seu representante em Spartaco, e os socialistas de hoje não luctam mais do que luctaram os Gracchos em Roma. Si assim é, mais rigoroso se mostra o dever de augmentar o patrimonio que nos foi legado.

Já se comparou a humanidade a um exercito em marcha, indo na vanguarda os batedores, os homens de idéas mais adeantadas; no centro, o grosso das tropas; e na retaguarda, os poucos que marcham com certa difficuldade. Ora, entre os que rompem a marcha, vão, em geral, os moços. A elles pois devo fazer appello para que sejam os combatentes da guarda avançada nesta tremenda campanha com que nos desafia o seculo XX.

As sciencias sociaes, do mesmo modo que as juridicas, provocam-nos a resolvermos os arduos problemas, parti- 
cularmente, os nascidos da grande guerra, cataclysmo que parece haver abalado o mundo inteiro, perturbando a marcha da civilização em nosso planeta.

Nesse campo de batalha, que se nos offerece nas sciencias juridicas e sociaes, na lucta pelo triumpho completo dos ideaes de hoje, teremos de enfrentar com as difficuldades impressionadoras do Direito Publico e do Privado.

O Direito Constitucional, não obstante suas promessas tão auspiciosas, firmadas na aurora do seculo XIX, graças á acção dos encyclopedistas, infelizmente soffreu em seu desenvolvimento acção corrosiva, constante, paciente e longamente exercida pelos espiritos reaccionarios, e comparavel á da gotta de agua que cava a pedra. As medidas regulamentares e a separação dos poderes sem um contraste, em França, os poderes de policia, na America do Norte, foram os agentes que, lentamente, mas com segurança, corroeram as concessões liberaes impetradas pelos idealistas que, em 1789, se sacrificaram pela humanidade soffredora, não regateando nem mesmo seu sangue derramado sob o cutelo da guilhotina.

O Direito Internacional, que se julgava, antes da guerra mundial, firmado na consciencia humana, e que se suppunha tão-fixo e rijo quanto a propria lei escripta, foi objecto do sarcasmo dos fortes no começo da lucta sem par. Finda que foi ella, começou a emprehendida para paz, que não tinha sido conquistada pelo tratado de Versalhes. Eis porém que espiritos investigadores, com trabalhos verdadeiramente de pacientes benedictinos, perscrutando, por documentos officiaes, as causas da horrenda guerra, desgraça da humanidade culta, chegaram á conclusão de terem sido os diplomatas, mais do que as testas coroadas, mais do que estratocracia organizada nas grandes potencias, os factores primordiaes do cataclysmo.

Esses homens que eram pagos pelos povos para serem os sustentaculos da paz, foram precisamente os que, trahindo sua missão, haviam desencadeado a tormenta sobre a humanidade. Conclusão ineluctavel é pois a de que cum- 
pre uma reforma radical no Direito das Gentes e na organização diplomatica.

o Direito Civil que, por tantos annos, se teve como sendo um producto da experiencia dos seculos, palladio contra as violencias dos poderosos da terra, foi posto em duvida em seus principios fundamentaes. Lei tida como sendo feita pelos fortes para exploração dos fracos, incapaz de acudir ás necessidades dos que foram desamparados pela natureza, e que pedem o soccorro de seus irmãos, começou a ser batido o Direito Civil, e profundos golpes lhe foram desferidos pelos reformadores, notadamente no que diz respeito á protecção do trabalhador em face do capital. Clamores se ergueram contra o Supremo Tribunal norte-americano que, firmado na letra da Constituição, se tornou um obice ao movimento social avassalador de todas as consciencias.

Viu-se que o commercio, com os trusts, com as poderosas sociedades anonymas, com os colossaes syndicatos, com a especulação em generos de primeira necessidade, era uma arma de oppressão do pobre, do trabalhador pelo rico, pelo capitalista e pelo millionario ou billionario.

Os jurisconsultos, abeberados hoje nos principios da Sociologia, sciencia nova, mas já de grande valor, entraram a mostrar-se scepticos acerca do jus certum (em que tanto confiavam os romanos do tempo das Leis das XII Taboas, confiança que se manifestou ainda em BAcon, quando sustentou dever a lei deixar um minimo de arbitrio ao juiz, mas que estava já muito combalida em SAvigny, quando o grande mestre asseverou ser um sonho irrealizavel o de um codigo a distribuir justiça automaticamente), e iniciaram a revolução nos processos classicos de interpretação das leis. O methodo tradicional perdeu seus crentes, e as escolas mais variadas e as sub-escolas tiveram seus adeptos, desde a teleologica e a evolutiva até a do Direito Livre, chəgando-se mesmo a proclamar que o juiz póde ir contra a lei!. 
Resuscitado em pleno seculo XX, tremeria Papiniano de horror, lendo as disposições do nosso Codigo Civil (embora summamente conservador, ao sentir actual), e perguntaria si é possivel que se mantenha uma sociedade com uma lei que nem mesmo os mais humildes dos plebeus romanos sonhariam. E é todavia necessario que muito façam ainda os moços para corresponderem aos anhelos da multidão que repete, ao lêr o texto da obra representativa do pensar actual, ser ella uma lei burgueza, inspirada no humanum paucis vivit genus, e exige a socialização do Direito, hoje victoriosa na consciencia de todos, e uma radical reforma da lei que entrou em vigor em 1917, precisamente quando a humanidade dava um salto, impellida pelas lições recebidas durante a grande guerra.

O sombrio Direito Penal offerece ao estudioso os mais graves problemas acerca desse lugubre phenomeno que se denomina crime. As discussões recrescem sobre a efficacia da pena, e pede-se á Criminologia uma noção exacta do crime natural, a determinação dos factores do crime, perguntando-se-lhe si é elle uma fatalidade inevitavel, á qual não póde fugir a humanidade. Neste comenos, augmenia a criminalidade na America do Norte, sem embargo das execuções capitaes, subindo a cerca de duas por dia na grande republica, que, dentro em pouco, rivalizará com a Allemanha ao tempo de Carpzov, o juiz que matou mais de vinte mil delinquentes. Será mais um record. 0 juiz norte-americano Kavanagh propõe, para solver o problema, augmento dos postos de açoites, pelourinhos por todos os cantos e a fundação de novos estabelecimentos penitenciarios, galés por todos os lados: prodigalidade de castigos. Bruce, o professor na Northwestern University, critica a opinião de Kavanagh, e mostra que é o desamparo da mocidade, o amoral ambiente a que ella é exposta nos Estados Unidos o factor quasi unico do augmento da delinquencia na terra de Marshall.

No Processo Criminal, não são menos difficeis as questões, que se nos antolham. Convencidos de que mau é o 
povo donde saem os jurados, sendo estes homens ignorantes ou protectores dos inimigos da ordem, sustentaram os inimigos do jury que, entregues nossa vida, nossa propriedade e nossa honra a um juiz culto e togado, tudo entraria em seus eixos, e, com effeito, o Estado de São Paulo e outros Estados da União, com o mais profundo desprezo pelas promessas constitucionaes, aboliram de facto o jury, confiando aos seus magistrados o julgamento dos delictos. Ora, como tem succedido em tantos outros paizes que tentaram esta aventurosa experiencia, foi um desengano para os inimigos do jury e uma surpreza para a opinião publica, manifestada pela imprensa, o primeiro julgamento importante proferido nesta capital por um juiz togado. Clamor maior houve em um só dia contra esse juiz, do que, no correr dos annos, contra todos os jurados.

Emfim, sem falar nos problemas economicos, hoje que a sciencia de Adam Smith soffreu tão profunda reforma, uma transformação radical mesmo, direi do Processo Civil. Quando, a 4 de Agosto de 1789, prometteu a nobreza da França processo gratuito e rapido ao povo amotinado e exigente, em razão da tomada da Bastilha, longe estavam todos de pensar que illusoria seria a promessa, e que ainda hoje haveria quem affirmasse não ter sido o juiz creado sinão para o rico, bastando para o pobre a policia! Quem supporia que Consentini proclamaria, no seculo $\mathrm{XX}$, ser o processo o ramo mas atrazado do Direito?! E assim é.

Pois bem! Correndo o pensamento pelos problemas sociaes e pelos juridicos, eis os mais prementes: organizações operarias, direito de parede, colligações, resistencia aos caprichos do capital, cooperativas, mutuo soccorro, regulamentação das fabricas e officinas, hygiene nas habitaçõ es operarias, fixação de horas de trabalho, repouso festivo, trabalho de mulheres, creanças e velhos, seguro para a velhice e para a molestia, serviço nocturno, repressão do truck system e do sweting system, reorganização do trabalho, perturbado pela guerra, emprego dos desoccupados, contracto collectivo. Neste sombrio momento que atravessa a hu- 
manidade tão rudemente provada pela grande guerra, esses problemas reclamam insistentemente solução. Ou solvel-os, ou ver a cultura hodierna, arcando-se sob o peso delles, desapparecer, como outrora foi pelas ondas do oceano coberta a velha Atlantida. São enigmas que desafiam a intelligencia dos moços, e que lhes dizem, do mesmo modo que a antiga Esphinge: ou tu me decifras, ou eu te devoro.

E' o dever dos moços, dos que entram para a vida publica, promover indefessamente reformas, verdadeiras valvulas de segurança, afim de evitarem a explosão que fatalmente se dará, tensos como se acham os espiritos nestes ultimos annos. Ou sábias medidas, ou o cataclysmo.

DR. JOÃO ARRUDA

Professor cathedratico de Philosophia do Direito 